Please do not remove this page

RMIT

UNIVERSITY

\title{
Environmental durability of z-pinned carbon fibre-epoxy laminate exposed to water
}

Mouritz, Adrian

https://researchrepository.rmit.edu.au/esploro/outputs/9921859153501341/filesAndLinks?institution=61RMIT_INST\&index=null

Mouritz, A. (2012). Environmental durability of z-pinned carbon fibre-epoxy laminate exposed to water.

Composites Science and Technology, 72(13), 1568-1574.

https://doi.org/10.1016/j.compscitech.2012.06.006

Document Version: Accepted Manuscript

Published Version: https://doi.org/10.1016/j.compscitech.2012.06.006

Repository homepage: https://researchrepository.rmit.edu.au

(C) 2012 Elsevier

Downloaded On 2023/04/26 18:50:29 +1000

Please do not remove this page 
Thank you for downloading this document from the RMIT Research Repository.

The RMIT Research Repository is an open access database showcasing the research outputs of RMIT University researchers.

RMIT Research Repository: http://researchbank.rmit.edu.au/

\section{Citation:}

Mouritz, A 2012, 'Environmental durability of z-pinned carbon fibre-epoxy laminate exposed to water ', Composites Science and Technology , vol. 72, no. 13, pp. 1568-1574.

See this record in the RMIT Research Repository at:

http://researchbank.rmit.edu.au/view/rmit:17863

Version: Accepted Manuscript

Copyright Statement: ( 2012 Elsevier

Link to Published Version:

http://dx.doi.org/10.1016/j.compscitech.2012.06.006 


\title{
ENVIRONMENTAL DURABILITY OF Z-PINNED CARBON FIBRE-EPOXY LAMINATE EXPOSED TO WATER
}

\author{
A.P. Mouritz* \\ School of Aerospace, Mechanical \& Manufacturing Engineering, RMIT University, GPO Box 2476, \\ Melbourne, Victoria, Australia 3000
}

\begin{abstract}
The influence of z-pins on the water absorption properties of a quasi-isotropic carbon fibre-epoxy laminate is assessed. Fibrous composite pins accelerate the moisture absorption rate and increase the total absorbed moisture concentration when the laminate is immersed in water. However, the moisture absorption properties of the laminate are not affected significantly by pins when exposed to hot and humid air. Water diffusion into the z-pinned laminate is aided by interfacial cracks between the pins and laminate. Also, the axial alignment of fibres within the composite pins in the through-thickness direction increases the water absorption rate. Pin pull-out tests reveal that water absorption reduces the mode I crack bridging traction load generated by pins by reducing the shear strength of the pin-laminate interface. This indicates that the mode I delamination toughness induced by pinning is weakened by moisture absorption.
\end{abstract}

\section{KEYWORDS}

A. Polymer-matrix composites (PMCs)

B. Environmental Degradation

B. Fracture toughness

Z-pins

\footnotetext{
* A.P. Mouritz

Tel: +61 399256269

e-mail: adrian.mouritz@rmit.edu.au
} 


\section{INTRODUCTION}

Z-pinned laminates are a class of continuous fibre reinforced polymer composite material that are reinforced in the through-thickness direction with fibrous composite or metal pins [1]. The pins increase the delamination fracture toughness [e.g. 2-5], impact damage resistance [6-8], damage tolerance [9] and joint properties [e.g. 10-14] by generating crack bridging traction loads. Pinned composites are used on a few types of military aircraft, including the FA-18 Superhornet and C17-Globemaster III heavy-lift transporter, and their aerospace applications may increase in coming years. An important consideration in the use of pinned laminates in aircraft structures is their environmental durability. The insertion of pins must not adversely affect the physical and mechanical properties when composite materials are exposed to the environmental operating conditions of the aircraft. One of the most important environmental conditions considered in the durability assessment of aircraft composite materials is long-term exposure to water vapour (humidity) at elevated temperature; which is known as the hot/wet environment. A large body of research into the durability of composite materials exposed to water has been published [e.g. 15-20]. Furthermore, numerous studies into the processes by which water is absorbed into the epoxy resins which are used as the matrix phase to aerospace-grade carbon fibre composites have been reported [e.g. 21-25]. No single theory can explain all the water absorption phenomena in polymers, and the precise mechanisms that control the diffusion kinetics are still unknown for many polymer systems. However, a moisture transport theory is generally applied to epoxy resins that consider the water to exist as free or bound molecules.

Diffusion by free water basically occurs by a kinetic process involving water molecules jumping between molecular-sized gaps in the polymer network under the driving force 
of the moisture concentration gradient. Bound water is less mobile, and involves the polar water molecules being hydrogen bonded to hydrophilic groups (e.g. polar hydroxyl (-OH) sites) in the polymer network.

While the water absorption properties and processes for polymers and polymer composites have been extensively studied [15-25], nothing has been reported on the moisture absorption properties of pinned laminates. The environmental durability of pinned laminates must be known, particularly when exposed to liquid water and humid air, as part of the certification assessment of structural composite materials used in aircraft.

A very limited amount of research has been reported on the moisture absorption behaviour of stitched laminates. Whiteside et al. [26] exposed carbon-epoxy T-shaped joints stitched with carbon or Kevlar fibre tows to water enriched with the hydrogen isotope deuterium $\left(\mathrm{D}_{2} \mathrm{O}\right)$ under hot/wet conditions $\left(77^{\circ} \mathrm{C}\right.$ and $95 \%$ relative humidity of $\mathrm{D}_{2} \mathrm{O}$ for four months), and then monitored the moisture absorption using nuclear reaction analysis of protons emitted by the heavy water. It was found that the water content was much higher at or near the stitches, with the moisture level being 2-3 times higher in the carbon stitches and about 4 times higher in the Kevlar stitches than in the laminate material away from the stitches. This work proved that stitches aided moisture ingress into laminates. Farrow et al. [27] found that hygrothermal cycling of stitched carbon-epoxy laminate did not alter the loss in in-plane static and fatigue compressive strengths compared to the unstitched laminate. Apart of these two studies, there is no 
other published work into the moisture absorption behaviour of other types of laminates with through-thickness reinforcement, including pinned composites.

This paper presents an investigation into the environmental durability of pinned carbon fibre-epoxy laminate when exposed to water. Carbon-epoxy was selected because it is the most common laminate material used in aircraft composite structures. Unpinned and pinned laminates were exposed to water under different environmental conditions for increasing periods up to nearly one year to assess the influence of fibrous composite pins on the moisture absorption behaviour. The effect of water absorption by the laminate on the mode I crack bridging traction properties of the pins was evaluated as part of the durability assessment. This was performed because the most important reason for pinning is to increase the interlaminar fracture toughness and damage tolerance properties of composites, and it is essential to determine whether moisture absorption changes the bridging traction properties of the pins.

\section{MATERIALS AND EXPERIMENTAL TECHNIQUES}

\subsection{Composite Materials}

Unpinned and pinned quasi-isotropic laminates were made using unidirectional T700 carbon-epoxy prepreg tape (VTM 264 supplied by Advanced Composites Group). The laminates were fabricated from 20 plies of the unidirectional tape stacked in the sequence $[0 /+45 / 90 /-45 / 0 /+45 / 90 /-45 / 0 / 90]_{s}$. The uncured prepreg laminate was reinforced in the through-thickness direction using pultruded fibrous composite pins made of unidirectional T300 carbon fibre-bismaleimide (BMI), known commercially as Z-Fiber $^{\mathrm{TM}}$ (Albany Engineered Composites Pty Ltd). The pins were inserted into the 
laminate using an ultrasonic hand-held device operated at the frequency of $20 \mathrm{kHz}$. A full description of the pinning process is given by Mouritz [1]. The volume content and diameter of the pins was $4 \%$ and $0.28 \mathrm{~mm}$, respectively. The tip of the pins which was driven into the laminate was chamfered to aid the insertion process whereas the trailing end of the pins was blunt. The laminates were cured and consolidated in an autoclave at $120^{\circ} \mathrm{C}$ and $620 \mathrm{kPa}$ for one hour. The average thicknesses of the cured unpinned and pinned materials were $4.36 \mathrm{~mm}$ and $4.51 \mathrm{~mm}$, respectively. Chang et al. [28] report that pinning can increase slightly the laminate thickness due to the volume occupied by the pins and the resistance the pins impose against preform consolidation within the autoclave.

Microstructural examination of the pinned laminates revealed the presence of voids within the pins, as shown in figure 1 . The voids were elongated along the pin length, and are caused by incomplete infiltration of the BMI resin during the pultrusion process used in pin manufacture. Debonding cracks were observed at the interface between the pins and laminate (figure 1b). These cracks extended partially (but not completely) around and along the pins, and therefore some interfacial bonding between the pin and laminate does occur. Sweeting and Thomson [29] report that interfacial cracks are formed during cool-down of the pinned laminate from the cure temperature due to the large difference in the orthotropic thermal expansion coefficients of the pins and laminate. The volume fraction of voids within the pins and the amount of debonding at the pin-laminate interfaces was not quantified, although they did vary between pins.

\subsection{Environmental Durability Tests}


Specimens of the unpinned and pinned laminates were exposed to four environmental conditions to assess the separated and combined effects of water and temperature on the moisture absorption properties. The specimens were flat coupons measuring $40 \mathrm{~mm} \mathrm{x}$ $40 \mathrm{~mm}$, and environmental testing commenced immediately after fabrication. The environmental tests conditions were as follows:

- $\quad$ Exposure to ambient atmospheric conditions $\left(20^{\circ} \mathrm{C}\right.$ and $50 \%$ relative humidity).

- Immersion in water at $20^{\circ} \mathrm{C}$.

- Immersion in water at $70^{\circ} \mathrm{C}$.

- $\quad$ Exposure to high temperature $\left(70^{\circ} \mathrm{C}\right)$ and high humidity $(85 \%)$.

The last environmental conditioning test replicated the standard hot/wet condition commonly used to assess the hygrothermal durability of aircraft composite materials. The hot/wet conditioning was performed using a Sunrise environmental chamber.

Three samples of the unpinned and pinned laminates were conditioned in each of the four environments for a total exposure time of nearly one year. The specimens were weighed at regular intervals over this period using a And HR-200 microbalance (to within an accuracy of $100 \mu \mathrm{g}$ ) to measure the weight gain due to moisture absorption. In addition, single pins were conditioned in water at $20^{\circ} \mathrm{C}$ or $70^{\circ} \mathrm{C}$ or in the hot/wet environment $\left(70^{\circ} \mathrm{C}\right.$ and $85 \%$ relative humidity) until saturation.

\subsection{Pin Pull-Out Test}

Pin pull-out tests were performed to assess the influence of environmental ageing on the crack bridging traction properties of the pins. As mentioned, the most important reason for the pin reinforcement of laminates is to increase the interlaminar properties such as 
delamination fracture toughness and impact damage resistance. The improvement to these properties is dependent on the bridging traction loads generated by the pins. The design of the pin pull-out specimen is presented in figure 2, and 64 pins were located in the central area measuring $10 \mathrm{~mm} \times 10 \mathrm{~mm}$ (which is equivalent to the pin volume content of $4 \%$ within the reinforced area). The specimens were manufactured from the same unidirectional carbon-epoxy prepreg, the plies were stacked in the same quasiisotropic pattern, and were cured and consolidated in an autoclave under the same conditions as the environmental test coupons. A thin film of PTFE (peel ply) was placed between the two middle plies to avoid bonding during curing of the pin pull-out samples. This resulted in two halves of the laminate of equal thickness ( $2 \mathrm{~mm}$ ) being separated by the peel ply. It is common practice in pin pull-out tests to locate the peel ply between the two middle plies to ensure symmetric load reactions by the pins in the two halves of the laminate specimen. Placing the peel ply at another location will result in anti-symmetric loading of the pins and possibly induce a different pin failure mode.

The samples were loaded in through-thickness tension at the constant crack opening displacement rate of $1 \mathrm{~mm} / \mathrm{min}$ until all the pins had failed. The total applied force was divided by the number of pins within the sample to determine the average traction load per pin. Three samples were tested under identical conditions for increasing exposure times in the hot/wet and hot water environments.

\section{$3 \quad$ RESULTS AND DISCUSSION}

\subsection{Effect of Pins on Water Absorption Properties}


Figure 3 shows plots of percentage weight gain against exposure time for the unpinned and pinned laminates when tested in the four environments. The exposure time is expressed as the square root of time on the lower axis and linear time on the upper axis. Figure 3a presents three curves each for the unpinned and pinned laminates exposed to ambient conditions $\left(20^{\circ} \mathrm{C}\right.$ and $50 \%$ relative humidity) which show the typical scatter in the weight gain values. There was excellent consistency in the weight gain of the three unpinned laminate samples, and this was also found for the other environmental test conditions. The pinned laminate showed greater variability in weight gain between samples, and again this was observed for this material tested in the other environments. The cause for the greater scatter in the weight gain measurements of the pinned laminate is explained later. The other plots in figure 3(b-c) show the average weight gain for the materials based on three samples exposed to the same environment.

The moisture absorption curves presented in figure 3 show an initial linear increase in weight for both the unpinned and pinned laminates, and as expected the absorption rate increased with the temperature and water concentration of the environment. The water absorption rate, defined by the gradient of the rectilinear portion of the curves, was higher for the pinned laminate compared to the unpinned material for all environmental conditions. Pins increased the water absorption rate by between $6 \%$ and $60 \%$, with the increase being much higher when the pinned laminate was immersed in water (at $20^{\circ} \mathrm{C}$ or $70^{\circ} \mathrm{C}$ ) compared to being exposed to humid air. The laminates did not reach full saturation when tested at $20^{\circ} \mathrm{C}$ in air for over 90 hours $^{1 / 2}$ (8100 hours), although it is expected that eventually these materials will saturate. The materials exposed to the hot and wet condition $\left(70^{\circ} \mathrm{C}\right.$ and $85 \%$ relative humidity) reached saturation and showed 
classical Fickian behaviour by maintaining a near constant percentage weight gain with increasing environmental ageing. The unpinned and pinned laminates tested in hot water also appeared to reach a saturated condition, however these materials did not maintain a constant weight due to the formation of delamination and matrix cracks due possibly to tensile strains induced by volumetric swelling [21,30,31]. The large percentage weight gain by these materials $(>2.5 \%)$ due to the high amount of water absorption is believed to have weakened the interfacial region between the carbon fibres and epoxy matrix by swelling which causes cracking. This type of damage has been observed in other types of laminates [32,33].

\subsection{Effect of Pins on Water Absorption Mechanisms}

The higher water absorption of the pinned laminate could be due to interfacial cracks, voids within the pins, and the alignment of fibres within the pins in the throughthickness direction, as shown schematically in figure 4. Single pins were exposed to $70^{\circ} \mathrm{C}$ water and the hot/wet environment to measure the weight gain due to the pin alone. The pins immersed in hot water gained about $0.8 \%$ weight at saturation, which is much less than the weight gained by the carbon-epoxy substrate ( 2.7\%). Boa and Yee [34] report that BMI resin (which is the polymer matrix to the fibrous pins) has similar diffusion activation energy and possibly similar diffusion mechanisms to epoxy resin. This suggests that the pins themselves were not responsible for the higher water absorption of the pinned laminate. This then implies that the pin-laminate interfacial cracks and possibly voids within the pins are the main causes for the higher water absorption. The interfacial cracks are expected to provide a pathway for the rapid ingress of water into the laminate. Also, the increased amount of water absorption due 
to interfacial cracking may account for the higher scatter in the weight gain measurements of the pinned laminate compared to the unpinned material (see figure 3a). As mentioned, the void content and the amount of interfacial cracking varied between pins. As a result, the water absorption is expected to vary between pins, and therefore this can create variability in the weight gained by pinned laminate samples.

The accelerated absorption of moisture by the pinned laminates may also be due to the rapid transport of water along the pins, which was found by Whiteside et al. [26] for stitches. While the pins absorbed less water than the host laminate, the alignment of their fibres in the through-thickness direction may aid moisture diffusion into the laminates. Shen and Springer [15] report that the water diffusion properties of carbon fibre laminates are anisotropic, with the diffusion coefficient along the fibre direction typically about one order of magnitude higher than in the transverse fibre direction. The higher diffusion rate in the fibre direction is due mostly to the fibre ends being exposed directly to water which allows moisture 'wicking' along the fibre-matrix interface. Because the pins were aligned in the water diffusion direction, it is believed that they create a pathway for the accelerated ingress of moisture into the laminate.

\subsection{Moisture Degradation of Pin Traction Properties}

The effect of moisture absorption on the efficacy of pins to resist mode I delamination cracking in the carbon-epoxy laminate was quantified using pin pull-out tests. Figure 5 shows pin traction load-crack opening displacement curves measured for different exposure times to the hot/wet and hot water environments. The curve for the pinned laminate in the original condition shows an initial linear increase in the traction load due 
to resistance imposed by the pin against pull-out [35-37]. The traction load reached a peak value, which was then immediately followed by a large load drop due to complete debonding of the pin from the laminate. A small percentage of pins also broke at this point. Beyond the peak load point, the traction load decreased gradually with increasing crack opening displacement due to progressive pull-out of the pins from the laminate substrate. All of the pins were pulled out from the same one-half of the laminate, which was the side where the pin tips were chamfered, as shown in figure 6. It is believed that the reduced interfacial contact area between the pin and laminate due to the chamfer caused it to be pulled more easily from the laminate than the other one-half of the pin without the chamfer.

The maximum pin traction load and the elastic pin traction energy were reduced by moisture absorption for the two environmental conditions, as shown in figure 7. The elastic traction energy was determined by the area under the pin traction loaddisplacement curve up to the peak load, over which phase of the pull-out test the pin reacted elastically to the applied tensile force. Both the elastic traction load and energy decreased with increasing exposure time before reaching low and constant values when the laminates were fully saturated with water. Figure 7 shows that the elastic traction load and energy were reduced by 60-70\%, which indicates significant weakening of the mode I interlaminar toughening generated by pinning. This weakening of the elastic pin traction properties is attributed to a loss in the interfacial shear strength between the pin and laminate due to moisture absorption. The mechanism responsible for the loss in interfacial strength was not identified, although it may have been caused by tensile 
strains (volumetric swelling) induced by the absorbed water and by plasticisation of the interfacial region.

When the pin is aligned in the orthogonal direction, the maximum pin traction load $\left(P_{\max }\right)$ is related to the shear strength of the pin-laminate interface $(\tau)$ by the expression [38]:

$P_{\max }=\tau \pi d_{p} h$

where $d_{p}$ is the pin diameter and and $h$ is the length portion of the pin carrying load before pull-out begins. Because $d_{p}$ and $h$ were constants in the pin pull-out test, the equation can be used to calculate the reduction to the interfacial shear strength which was the cause for the deterioration of the elastic pin traction load. Figure 8 shows that the interfacial shear strength between pin and laminate is predicted to decrease progressively with increasing exposure time for both the hot/wet or hot water conditions. The interfacial strength is believed to decrease initially at the laminate surface exposed directly to the environment, and then move along the pin-laminate interface with increasing exposure time until the shear strength is uniformly weakened along the interface when the material is fully saturated. It is well known that moisture weakens the interfacial strength between fibres and polymer matrix in laminates [e.g. $17,18,30,31]$, and it is feasible that a similar mechanism weakens the pin/laminate interface in the carbon-epoxy materials studied here.

The applied force needed to overcome the friction stress at the pin-laminate interface during the pin pull-out phase is also important in the mode I interlaminar toughening of 
pinned laminates. The traction load generated by a pin during the pull-out phase can be calculated using [38]:

$P(\delta(S))=(H-S) \tau_{f} \pi d_{p}$

where $\tau_{f}$ is the interfacial friction stress opposing pin pull-out, $H$ is the half-thickness of laminate, and $S$ is the pin slip length due to pull-out. Using this equation, the interfacial friction stress during pin pull-out was calculated. It was found that the friction stress generated by pin pull-out was not degraded significantly by exposure to water.

\section{CONCLUSIONS}

Z-pin reinforcement of carbon-epoxy laminates increases the moisture absorption rate when fully immersed in water but not when exposed to humid air. Pins provide a pathway for water ingress via interfacial cracks between the pins and laminate as well as via the fibres within the pins being aligned in the through-thickness reinforcement. These factors increase the moisture diffusivity in pinned laminates, particularly when fully immersed in water. As expected, the moisture absorption rate of the pinned laminate increases with the temperature and water concentration of the atmosphere. Water absorption reduces the crack traction load and elastic traction energy generated by the pins under mode I interlaminar loading. The elastic traction properties are reduced by moisture reducing the shear strength of the pin-laminate interface. Water absorption does not reduce significantly the friction-induced traction load generated during the pin pull-out phase. This research has proven that the major reason for the pin reinforcement of composites - increased interlaminar fracture toughness - is adversely affected by water absorption, and therefore pinned laminates should be protected from 
moisture using water resistant (hydrophobic) coatings or some other method to prevent water ingress with the objective of retaining high crack bridging traction loads.

The research reveals that moisture absorption reduces the crack bridging traction loads responsible for the high mode I delamination toughness of pinned laminates. When moisture absorption causes significant interlaminar weakening of pinned materials, then other delamination toughening methods such as thermoplastic or fibre interleaving may be more environmentally resistant [e.g. 39,40]. Studies have shown that the delamination toughening effect is not reduced significantly and, in some laminates, is improved by moisture absorption via plasticisation or increased fibre bridging of the interleaved material.

\section{ACKNOWLEDGEMENT}

The author thanks R. Ryan of RMIT University for technical assistance in the manufacture of the joint specimens and B. Crisp, L. Edwards and L. Walker for some of the test measurements.

\section{References}

1. Mouritz AP. Review of z-pinned composite laminates, Comp. 2007;38A:2383-2397.

2. Rugg KL, Cox BN, Massabò R. Mixed mode delamination of polymer composite laminates reinforced through the thickness by z-fibres, Comp. 2002;33:177-190.

3. Yan W, Liu H-Y, Mai Y-W.Numerical study of the mode I delamination toughness of z-pinned laminates, Comp Sci \& Tech, 2003;63:1481-1493.

4. Cartié DDR, Cox BN, Fleck BN. Mechanisms of crack bridging by composite and metallic rods, Comp, 2004;35A:1325-1336.

5. Yan W, Liu H-Y, Mai Y-W. Mode II delamination toughness of z-pinned laminates, Comp Sci \& Tech, 2004;64:1937-1945.

6. Mouritz AP, Chang P, Isa MD. Z-pin composites: Aerospace structural design considerations, J Aero Eng, 2011;24:425-432.

7. Rezai A, Cartié D, Partridge I, Irving P, Aston T, Negre P, Langer J. Interlaminar damage resistance of $z$-fibre ${ }^{\mathrm{TM}}$ reinforced structural CFRP, In: Proceedings of the $13^{\text {th }}$ International Conference on Composite Materials, 25-29 June 2001, Beijing. 
8. Isa MD, Feih S, Mouritz AP. Compression fatigue properties of z-pinned quasiisotropic carbon/epoxy laminate with barely visible impact damage, Comp Struct, 2011;93:2222-2230.

9. Koh TM, Isa MD, Chang P, Mouritz AP. Improving the structural properties and damage tolerance of composite joints using z-pins, J Comp Mats, (in press).

10. Chang P, Mouritz AP, Cox BN. Tensile properties and failure mechanisms of zpinned composite lap joints, Comp Sci \& Tech, 2006;66:2163-2176.

11. Cartié, D.D.R., Dell’ Anno, G., Poulin, E. and Partridge, I.K., 3D reinforcement of stiffener-to-skin T-joints by z-pinning and tufting, Eng Fract Mech, 2006;73:25322540.

12. Li R, Huong N, Crosky A, Kelly D, Chang P, Mouritz AP. Improving the bearing performance of composite bolted joints using z-pins, Comp., 2009:69A:883-889.

13. Koh TM, Feih S, Mouritz AP. Experimental determination of the structural properties and strengthening mechanisms of z-pinned composite T-joints, Comp Struct, 2011;93:2269-2276.

14. Toral Vazquez J. Castanie B, Barrau J-J, Swiergiel N. Multi-level analysis of lowcost z-pinned composite joints. Part 2: joint behaviour, Comp. 2011;42A:20822092.

15. Shen C-H, Springer GS. Mositure absorption and desorption of composite materials, J Comp Mats, 1976;10:2-20.

16. Choi HS, Ahn KJ, Nam J-D, Chun HJ. Hygroscopic aspects of epoxy/carbon fiber composite laminates in aircraft environments, Comp., 2001;31A:709-720.

17. Kootsookos A, Mouritz AP. Seawater durability of glass- and carbon-polymer composites, Comp Sci \& Tech., 2004;64:1503-1511.

18. Ray BC. Temperature effect during humid ageing on interfaces of glass and carbon fibers reinforced epoxy composites, J Colloid \& Interface Sci, 2006;298:111-117.

19. Mourad A-HI, Beckry Mohamed AM, El-Maaddawy T. Effect of seawater and warm environment on glass/epoxy and glass/polyurethane composites, App Comp Mats, 2010;17:557-573.

20. Hossain MK, Imran KA, Hosur MV, Jeelani, S. Degradation of mechanical properties of conventional and nanophased carbon epoxy composites in seawater, $\mathrm{J}$ Eng Mats \& Tech., 2011;133:Article number 041004.

21. Vanlandingham MR, Eduljee RF, Gillespie JW. Moisture diffusion in epoxy systems. J App Poly Sci. 1999;71:787-798.

22. Nogueira P, Ramirez C, Torres A, Abad MJ, Cano J, Lopez J, Lopez-Bueno I, Barral L. Effect of water sorption on the structure and mechanical properties of an epoxy resin system. J App Poly Sci. 2001;80:71-80.

23. Li L, Zhang SY, Chen YH, Liu MJ, Ding YF, Luo XW, Pu Z, Zhou WF, Li S. Water transportation in epoxy resin. Chem Mater. 2005;17:839-845.

24. Lin YC, Chen X. Investigation of moisture diffusion in epoxy system: Experiments and molecular dynamic simulations. Chem Phy Letts. 2005;412:322-326.

25. Popineau S, Rondeau-Mouro C, Sulpice-Gaillet C, Shanahan MER. Free/bound water absorption in epoxy resin. Polymer. 2005;46:10733-10740.

26. Whiteside JB, Delasi RJ, Shutle RL. Measurement of preferential moisture ingress in composite wing spar joints. Comp Sci Tech. 1985;24:123-145.

27. Furrow KW, Loos AC, Cano RJ. Environmental effects on stitched textile composites. J Rein Plas Comp. 1996;15:378-419. 
28. Chang P, Mouritz AP, Cox BN. Properties and failure mechanisms of z-pinned laminates in monotonic and cyclic tension. Comp. 2006;37A:1501-1513.

29. Sweeting RD, Thomson RS. The effect of thermal mismatch on z-pinned laminated composite structures, Comp Struct, 2004;66:189-195.

30. Drzal LT, Rich MJ, Koenig MJ. Adhesion of graphite fibers to epoxy matrices. III. The effect of hygrothermal exposure. J Adhes. 18:1985:49-72.

31. Biro DA, Pleizier G, Deslandes Y, Application of the microbond technique: Effects of hygrothermal exposure on carbon-fiber/epoxy interfaces, Comp. Sci Tech., 1993;46:293-301.

32. Dewimille B, Bunsell AR. Accelerated ageing of a glass-fiber reinforced epoxy resin in water. Comp. 1983;14:35-40.

33. Zhou J, Lucas JP. The effects of a water environment on anomalous absorption behavior in graphite/epoxy. Comp. Sci. Tech. 1996;53:57-64.

34. Bao L-R, Yee AF. Effect of temperature on moisture absorption in a bismaleimide resin and its carbon composite, Polymer, 2002;43:3987-3997.

35. Dai SC, Yan W, Liu HY, Mai YW. Experimental study on z-pin bridging law by pullout test. Comp. Sci. Tech. 2004;64:2451-7.

36. Zhang A, Liu H, Mouritz AP, Mai Y. Experimental study and computer simulation on the degradation of z-pin reinforcement under cyclic fatigue. Comp. 2008;39A:406-14.

37. Cartié DDR, Cox BN, Fleck NA. Mechanisms of crack bridging by composite and metallic rods. Comp. 2004;35A:1325-36.

38. Jain LK, Wetherhold RC. The effect of fibre extensibility on the fracture toughness of short fibre/brittle matrix composites. App Mech Reviews, 1992;45:377-389.

39. Yasaee M, Bond IP, Trask RS, Greenhaugh ES. Mode I interfacial toughening through discontinuous interleaves for damage suppression and control. Comp. 2011;43:198-207.

40. Sohn M-S, Hu X-Z. Mode II delamination toughness of carbon fibre/epoxy composites reinforced with chopped Kevlar fibre reinforcement. Comp Sci Tech. 1994;52:439-448. 


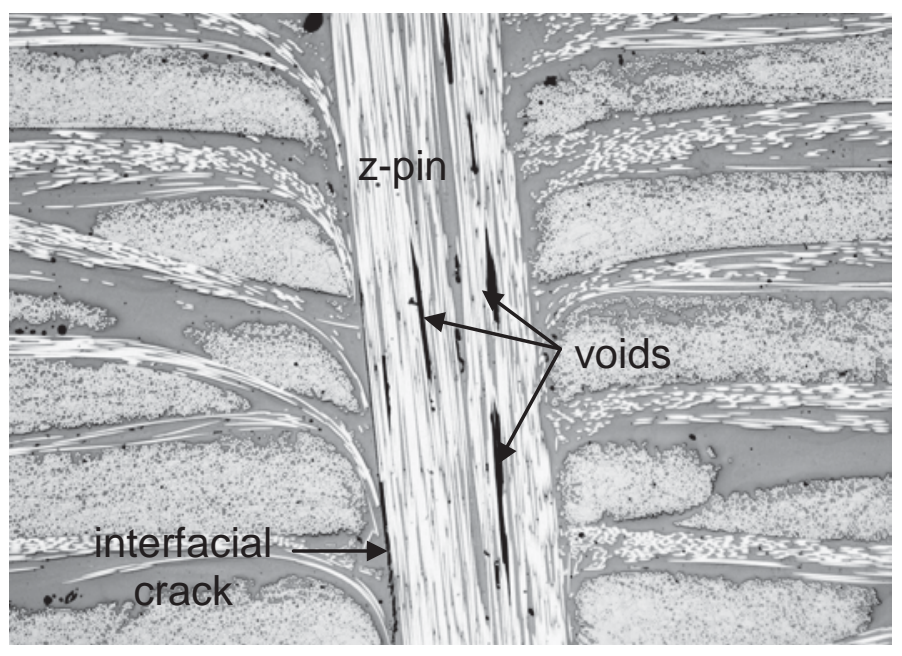

$300 \mu \mathrm{m}$

(a)

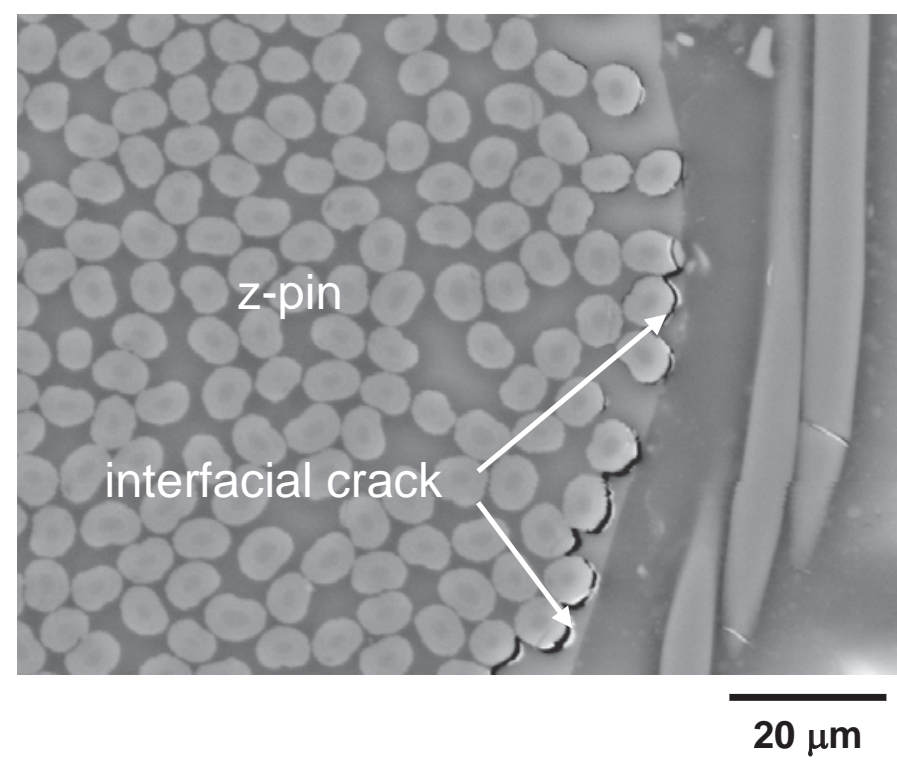

(b)

Figure 1. (a) Cross-section view of a pinned laminate showing voids elongated along the pin. (b) Planar view of a pin showing cracks at the interface with the laminate. 

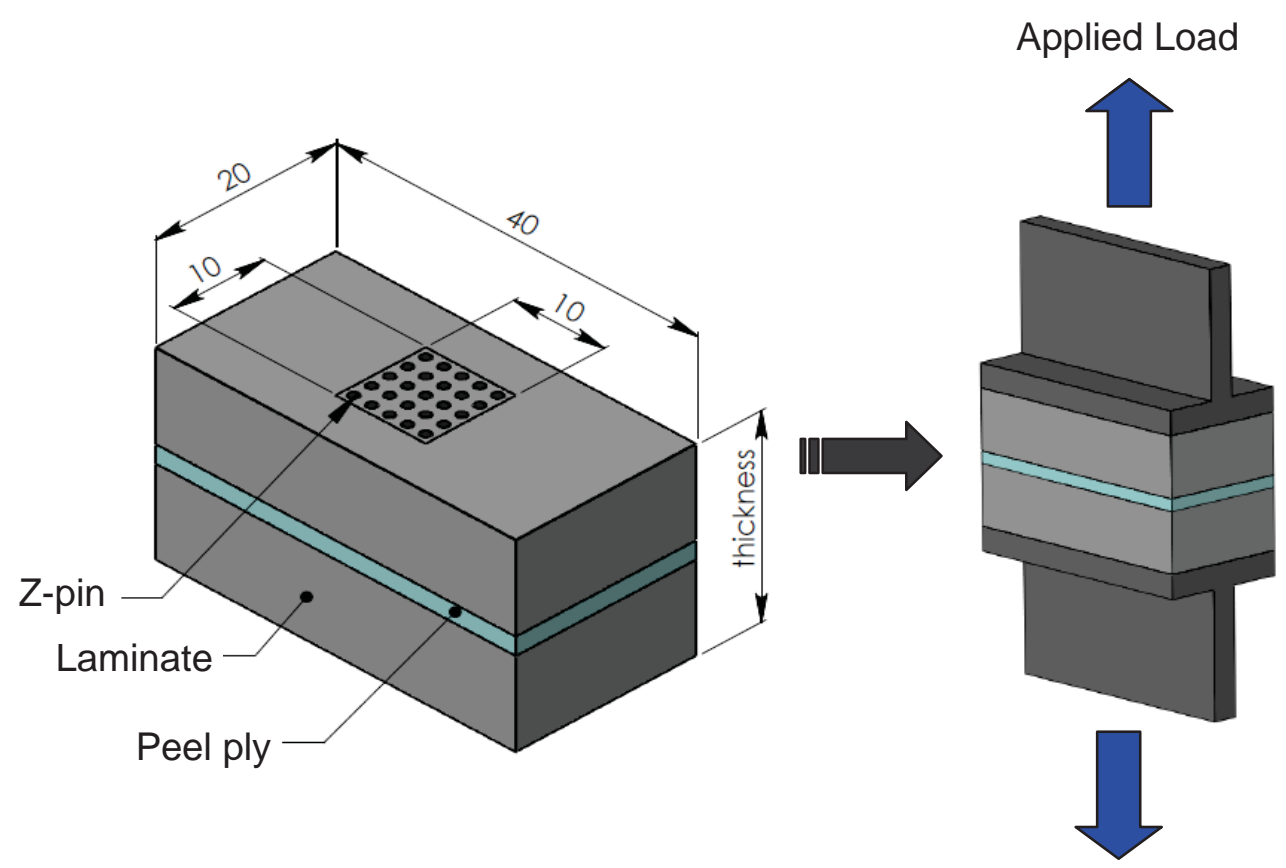

Applied Load

Figure 2. (a) Schematic of pin pull-off test specimen. (b) Load condition on specimen. 
Exposure Time (days)

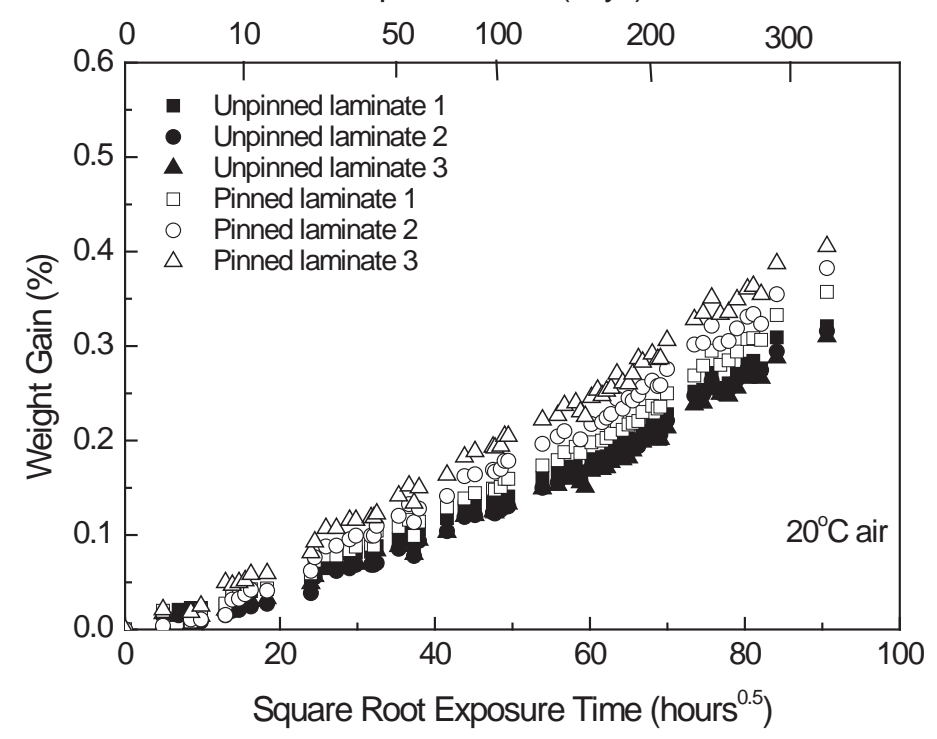

(a)

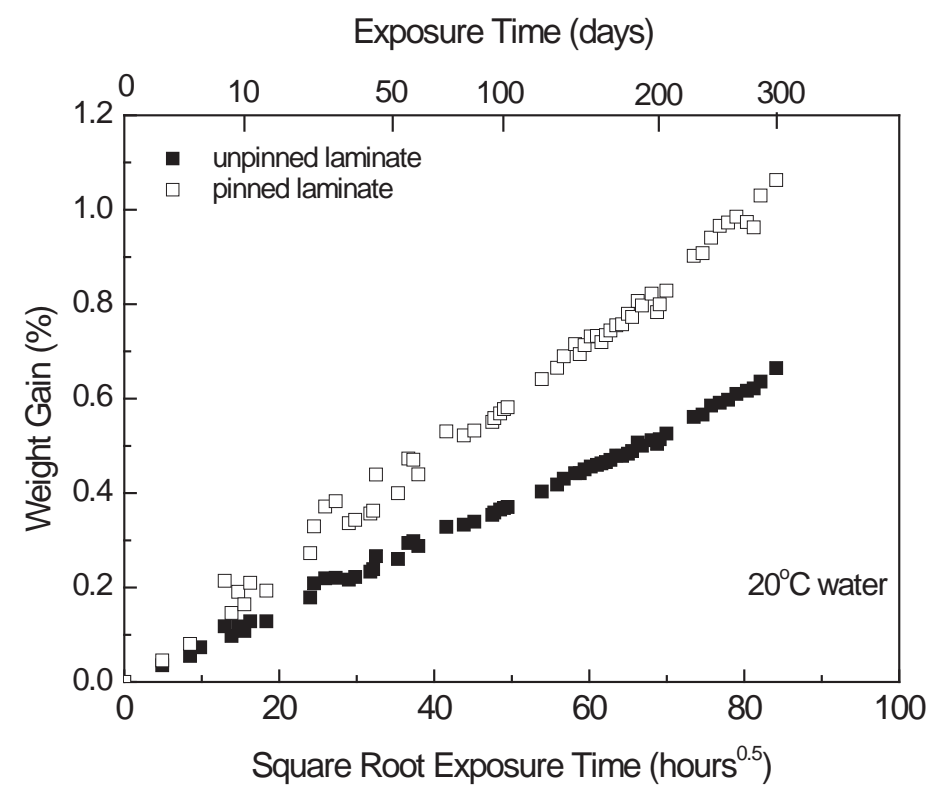

(b) 


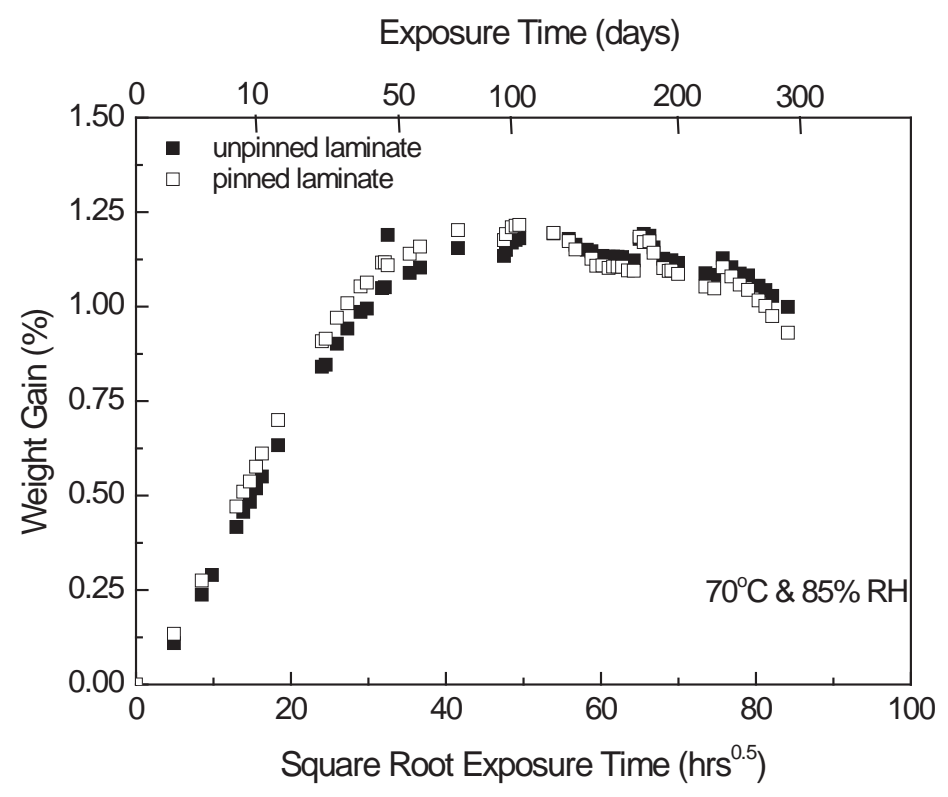

(c)

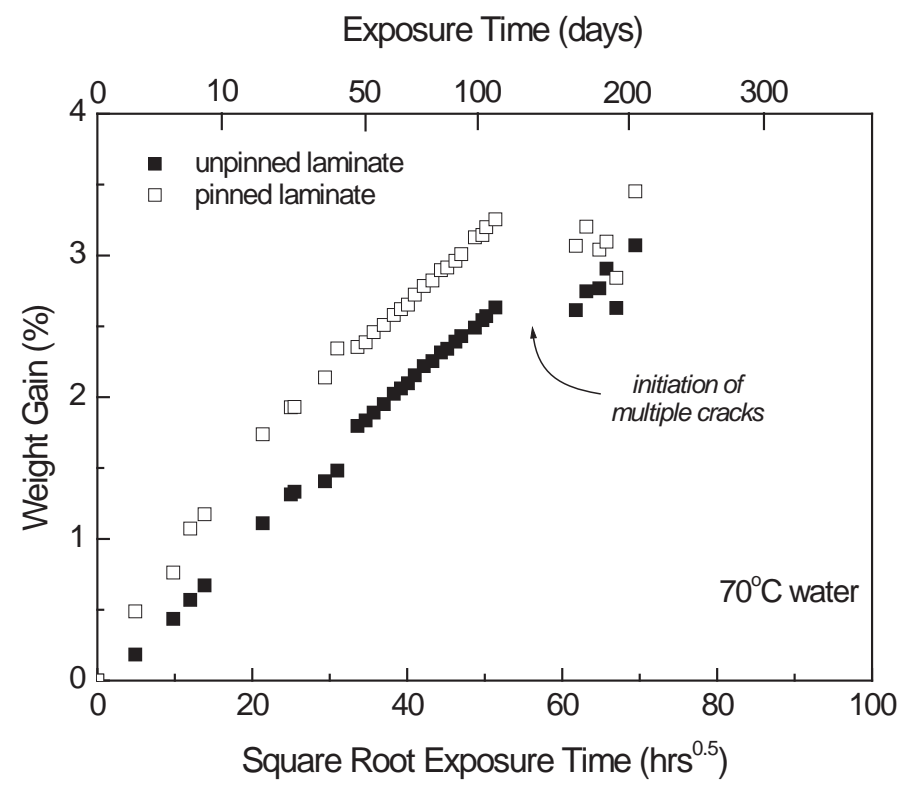

(d)

Figure 3. Percentage weight gain-exposure time curves for the unpinned and pinned laminates. The exposure conditions were (a) $20^{\circ} \mathrm{C}$ in air, (b) $20^{\circ} \mathrm{C}$ in water, (c) $70^{\circ} \mathrm{C}$ and $85 \%$ relative humidity (hot/wet) and (d) $70^{\circ} \mathrm{C}$ in water. Three curves for both materials are presented in (a) to show the typical scatter in the weight gain values between samples. The curves in (b) - (d) are the average weight gain curves based on three samples. 


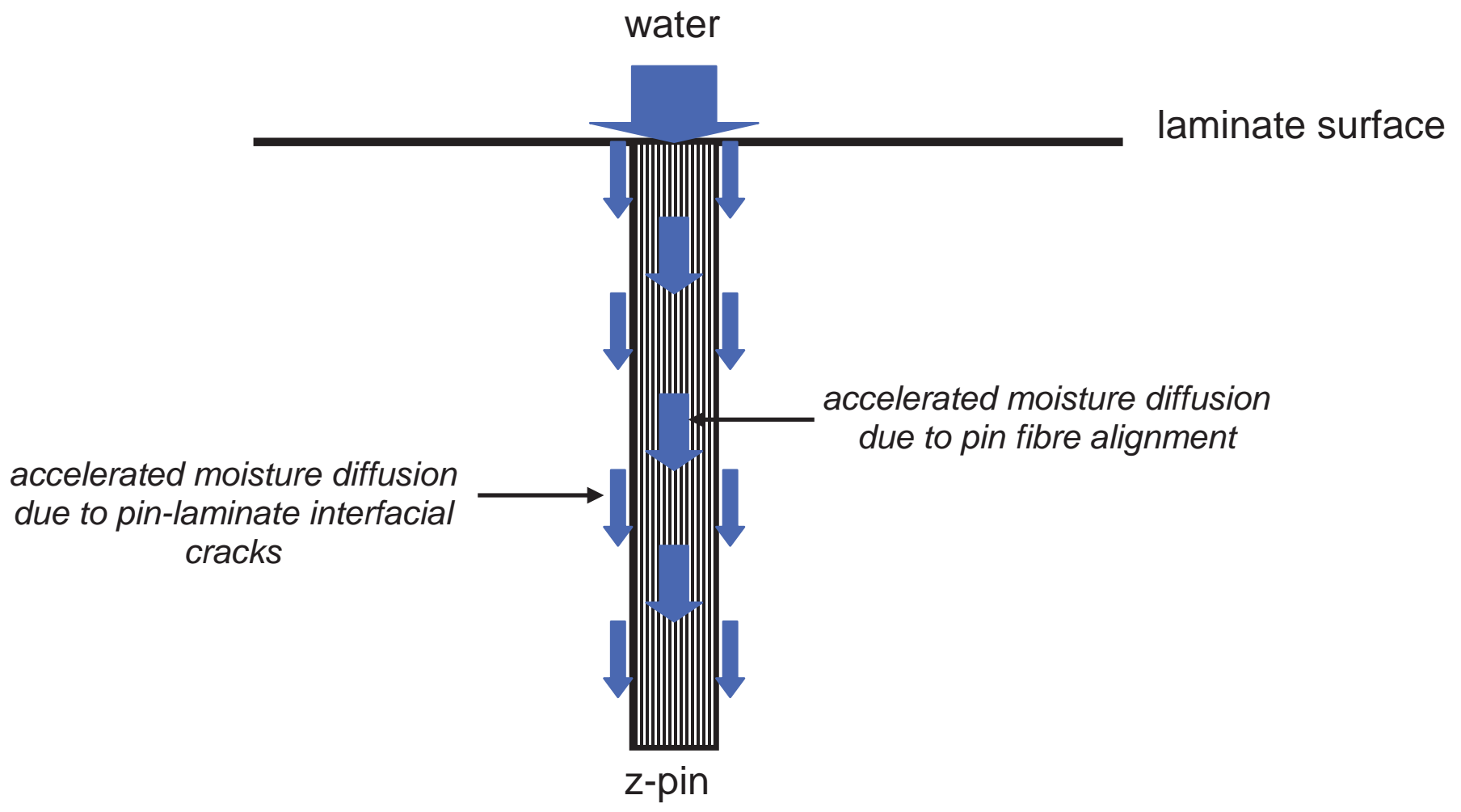

Figure 4. Schematic of the moisture absorption mechanism of the pinned laminate. 


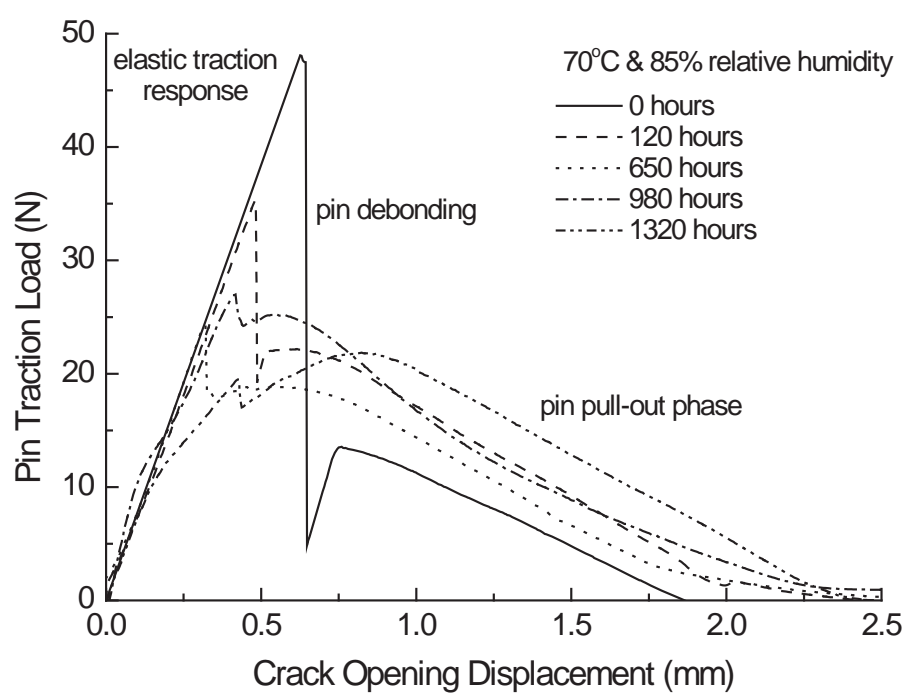

(a)

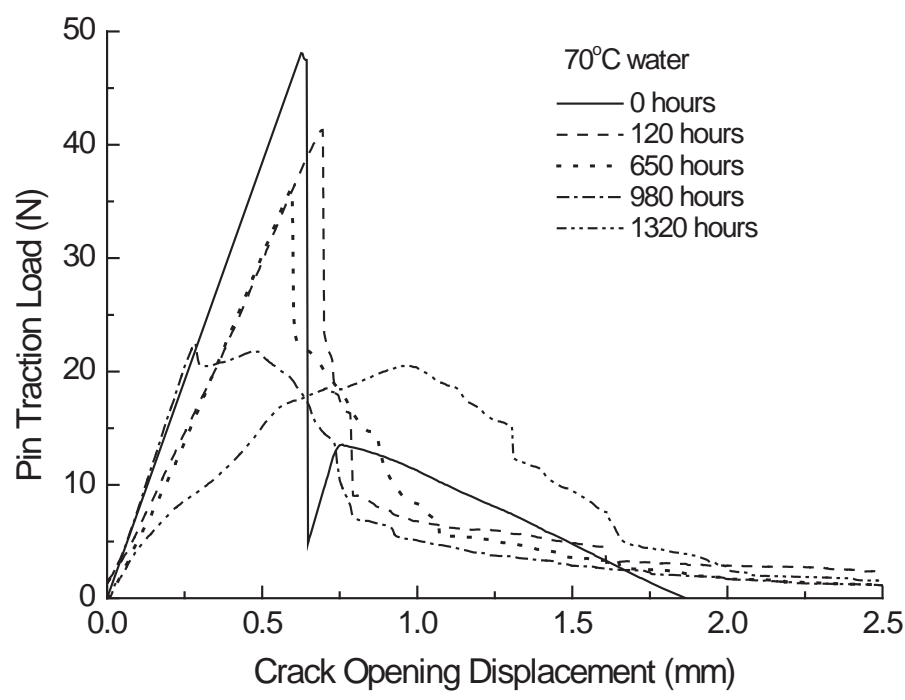

(b)

Figure 5. Pin traction load curves for the laminate exposed to (a) $70^{\circ} \mathrm{C}$ and $85 \%$ relative humidity and (b) $70^{\circ} \mathrm{C}$ water for increasing exposure times. 


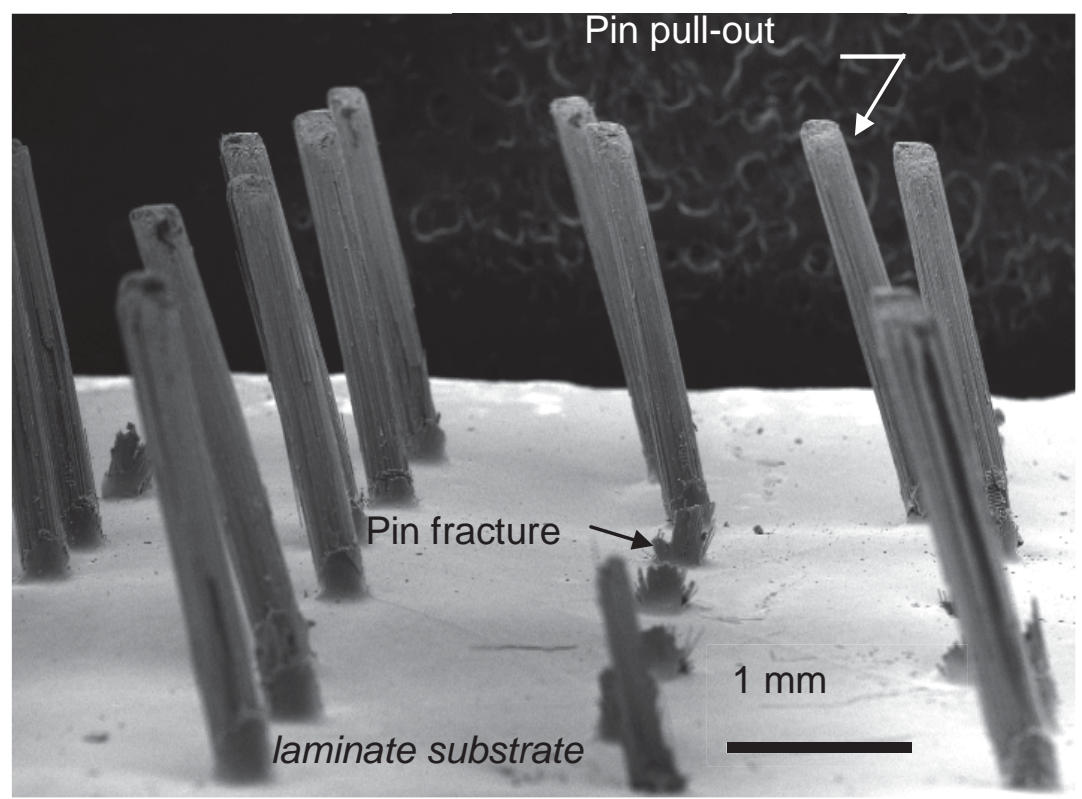

(a)

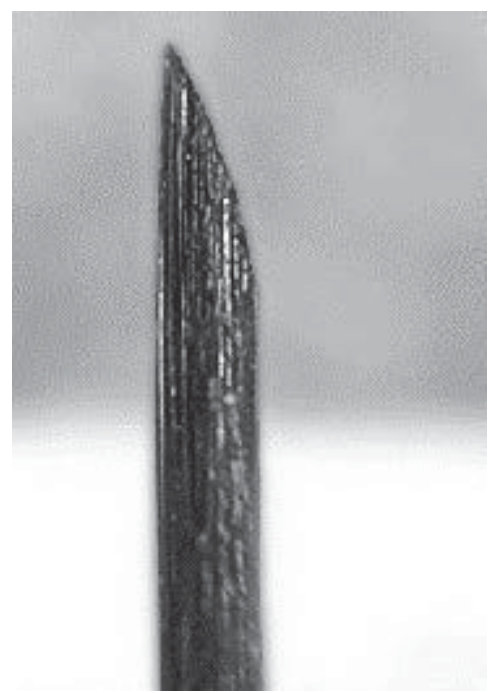

(b)

Figure 6. (a) Fracture surface of a pinned pull-out specimen showing most pins were pulled from the laminate substrate and a few pins broke. (b) The pins were always pulled from the one-half of the laminate specimen containing the chamfered end. 


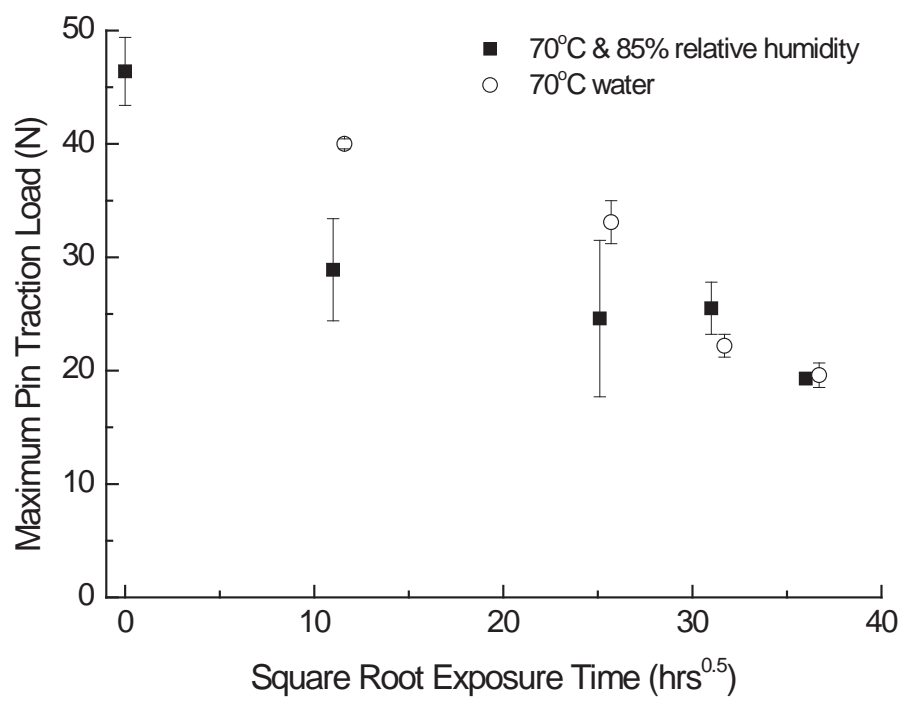

(a)

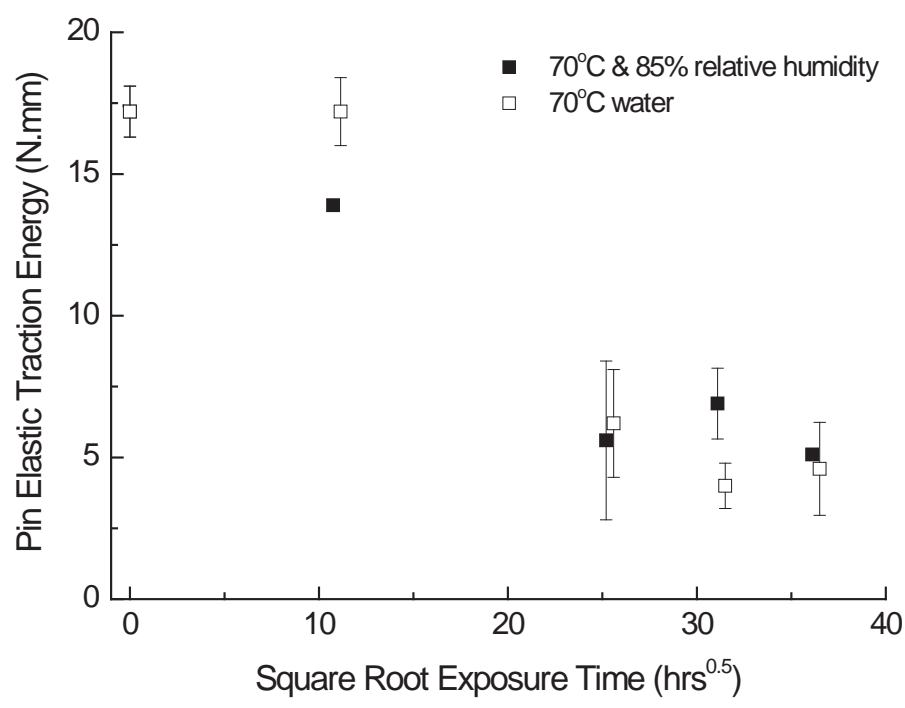

(b)

Figure 7. Effect of increasing exposure time on the (a) maximum pin traction load and (b) pin elastic traction energy. 


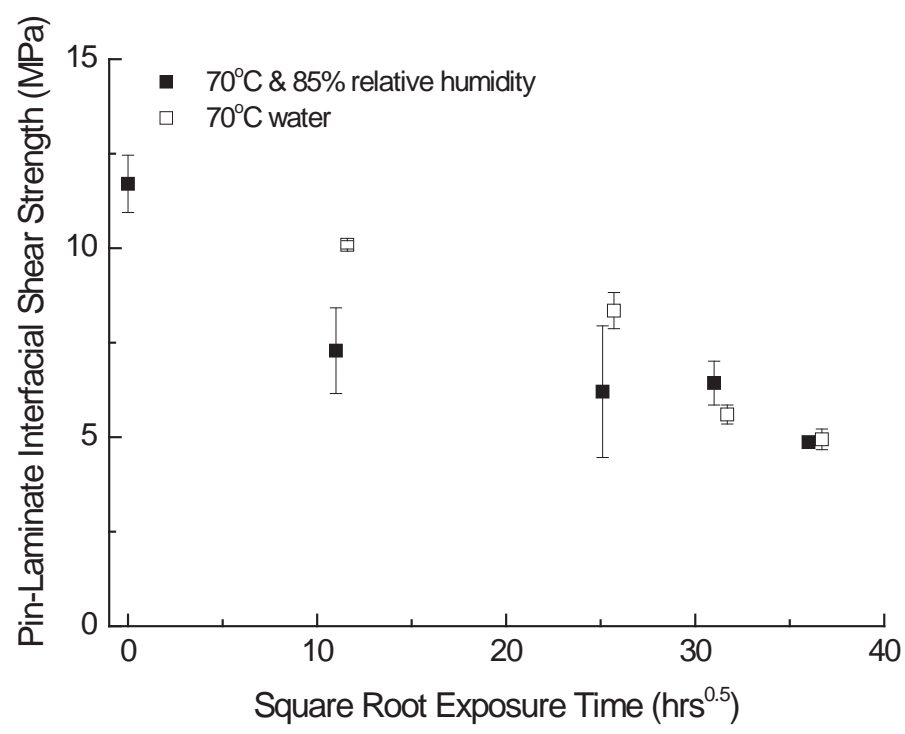

Figure 8. Effect of increasing exposure time on the interfacial shear stress between the pin and laminate. 